\title{
УЧЕТ АРЕНДЫ: ВОПРОСЫ И ПРОБЛЕМЫ У АРЕНДАТОРА.
}

\author{
(c) 2021 Блинова У.Ю. \\ доктор экономических наук, профессор Департамента аудита и корпоративной отчетности \\ Финансовый университет при Правительстве РФ, Россия, Москва \\ E-mail: ublinova@fa.ru \\ (c) 2021 Голышева Н.И. \\ кандидат экономических наук, доцент Департамента аудита и корпоративной отчетности \\ Финансового университета при Правительстве РФ, Россия, Москва \\ E-mail: ngolysheva@fa.ru
}

В 2022 году вступает в силу на территории РФ новый стандарт бухгалтерского учета ФСБУ 25/2018 «Бухгалтерский учет аренды». Организации, начиная применять данный стандарт, сталкиваются с такими новыми понятиями и определениями как «право пользование активом», дисконтированная стоимость, приведенная стоимость будущих арендных платежей. Правильный экономический и финансовый смысл этих понятий, их использование в практике применения нового стандарта имеет важное значение для эффективного ведения бухгалтерского учета и формирования показателей отчетности.

Ключевые слова: бухгалтерский учет, МСФО, операционная аренда, финансовая аренда, арендатор, право пользования активом, дисконтированная стоимость, приведенная стоимость, справедливая стоимость.

Сдача в аренду и аренда имущества актуальна во все времена и особенно в рыночных отношениях, когда можно не иметь имущества в собственности, но организовать производственный процесс, арендовав имущество без лишних трат и обязанностей.

В соответствии с Гражданским законодательством, заключая договор аренды, арендодатель обязуется предоставить арендатору имущество за плату во временное владение и пользование или во временное пользование.

Заключая договор аренды, арендодатель должен обязательно указать данные, позволяющие четко идентифицировать имущество, передаваемое в качестве объекта аренды. В случае, если этих данных не будет, договор будет считаться не заключенным.

В соответствии с условиями договорааренды он заключается на определенный срок, если срок не определен, договор аренды считается заключенным на неопределенный период.

В российской практике учета принят новый стандарт ФСБУ 25/ 2018 « Бухгалтерский учет аренды», который официально вводится в действие с отчетности за 2022 год, то есть, его необходимо применять в учетной практике уже начиная с 2022 года для отражения операций по аренде. Стандарт не запрещает и более раннее его применение организациями, например с 2019 или 2020 или 2021 года, в этом случае они должны это указать в пояснениях к бухгалтерской отчетности.

Данный стандарт вводит новые понятия применительно к аренде вместо ранее используемых. Вместо текущей аренды теперь предлагается применять термин “операционная” аренда, а вместо лизинга - “неоперационная” или “финансовая” аренда.

Стандарт оговаривает условия, когда в бухгалтерском учете можно говорить об объектах учета аренды, как показано на рисунке 1:

Критерии отнесения и определения договоров аренды к операционной или финансовой аренде недостаточно формализованы и допускают неоднозначное толкование, например, если договор аренды заключен на неопределенный срок (рисунок 2). В любом случае, если можно четко признать, что аренда операционная или как мы сказали бы раньше текущая, в этом случае учет, можно вести по-старому, как и до принятия ФСБУ 25/2018 (рисунок 3).

В процессе контроля и аудита договоров аренды возможны субъективные оценки в отнесении договоров к тому или другому типу 
- арендодатель предоставляет арендатору предмет аренды на определенный срок;

- предмет аренды идентифицируется (и не предусмотрено право арендодателя по своему усмотрению заменить предмет аренды в любой момент в течение срока аренды);

- арендатор имеет право на получение экономических выгод от использования предмета аренды в течение срока аренды;

- арендатор имеет право определять цель использования предмета аренды.

Puc. 1. Условия признания объектов учета аренды.

Договоры, срок которых не превышает 12 месяцев

Договоры, в которых предмет аренды имеет низкую стоимость ( $\leq 300$ ооо руб.)

Арендатор, имеющий право применять упрощенные способы бухгалтерского учета

Puc. 2. Критерии признания операционной аренды.
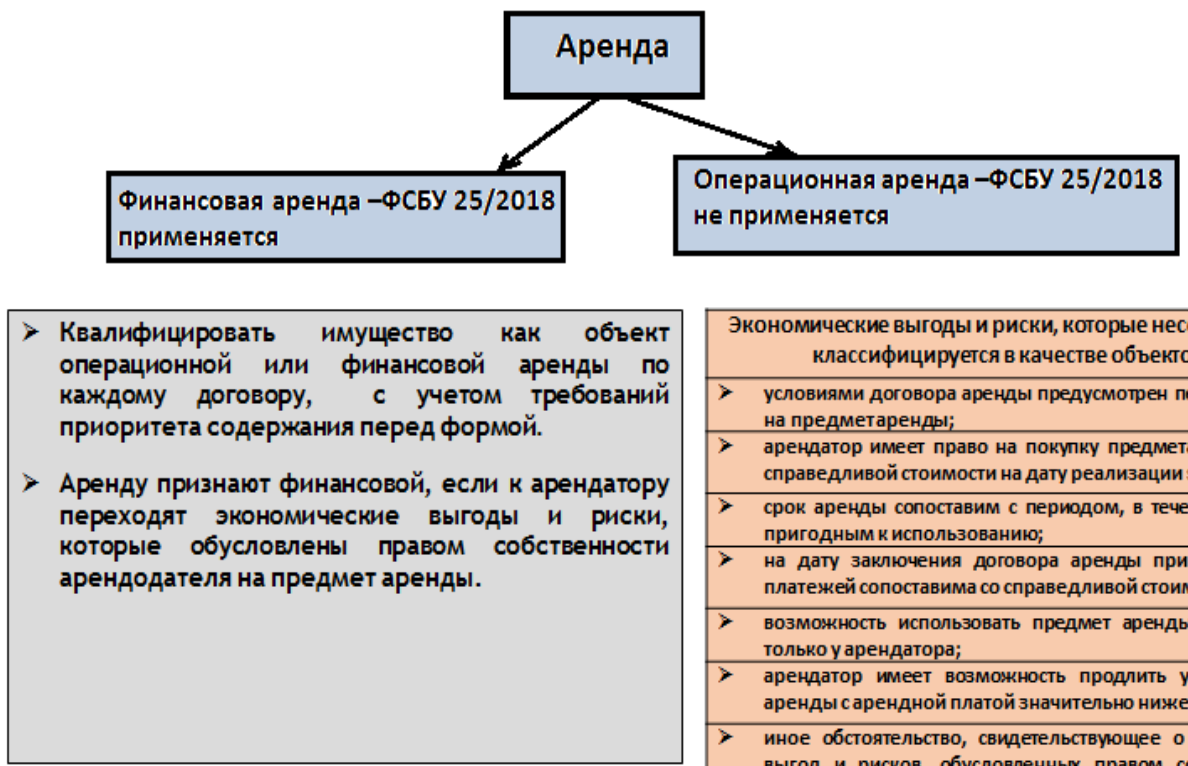
Экономические выгоды и риски, которые несет арендатор, когда предмет аренды, классифицируется в качестве объектов учета финансовойаренды.
$>$ условиями договора аренды предусмотрен переход к арендатору права собственности на предметаренды; спендатор имеет право на покупку предмета аривой стоимости на дату реализации этого права;
срок аренды сопоставим с периодом, в течение которого предмет аренды останется пригодным к использованию;
на дату заключения договора аренды приведенная стоимость будущих ареңдных платежей сопоставима со справедливой стоимостью предмета аренды;
возможность использовать предмет аренды без существенных изменений имеется только уарендатора;
ареңдатор имеет возможность продлить установленный договором аренды срок аренды с арендной платой значительно нижерыночной;
$>$ иное обстоятельство, свидетельствующее о переходе к арендатору экономических выгод и рисков, обусловленных правом собственности арендодателя на предмет аренды.

Puc. 3. Признаки финансовой аренды. 
аренды. Например, если договор заключен на 10 месяцев, затем, после перерыва в несколько месяцев, опять заключен на 11 месяцев, затем опять прервался и перезаключен, или если в течение срока аренды изменились условия и арендатор или арендодатель принимает решение изменить условия аренды.

Получается, что для целей бухгалтерского учета и арендатор и арендодатель должны четко определиться на какой срок арендуется или сдается имущество в аренду, определиться с целью аренды, а это не всегда согласовывается с юридическими нормами заключения договоров.

Кроме того, возникают вопросы по аренде имущества, стоимость которого к концу срока аренды становятся дороже, чем в начале предоставления его в лизинг. Так происходит с некоторыми экземплярами уникальных автомобилей, которые к концу срока аренды становятся дороже, или, например, при аренде зданий, как правило, их стоимость к концу срока аренды остается такой же, как и в начале или даже значительно больше их выкупной стоимости.

Арендатор при получении имущества в аренду, принимает его к учету и определяет такой новый объект учета, как сумму право пользованием активом. В учете делается проводка Дебет ППА., или Дебет 08 «Права пользования».
Одновременно определяется обязательство по аренде - Кредит ОА., или Кредит 76 «Обязательство по аренде»

Иными словами, в учете арендатора появляется новый объект учета - право пользованием активом-ППА, и надо отметить, что рассчитать его не так-то просто. Приведем порядок расчета приведенной стоимости ППА на рисунке 4.

Итак, право пользования активом принимается к учету по фактической стоимости. Порядок формирования фактической стоимости права пользования активом представлен на рис. 4 .

Оценочным обязательством может быть: планируемые затраты по демонтажу, перемещению предмета аренды, восстановлению окружающей среды, восстановлению предмета аренды до требуемого договором состояния, если это предусмотрено договором аренды.

Обязательство по аренде первоначально оценивается как сумма приведенной стоимости будущих арендных платежей на дату этой оценки.

Приведенная стоимость будущих арендных платежей определяется путем дисконтирования их номинальных величин по формуле, указанной на рисунке 5:

Основной вопрос и проблема, которая возникает при расчете приведенной стоимости это ставка дисконтирования (рисунок 6).

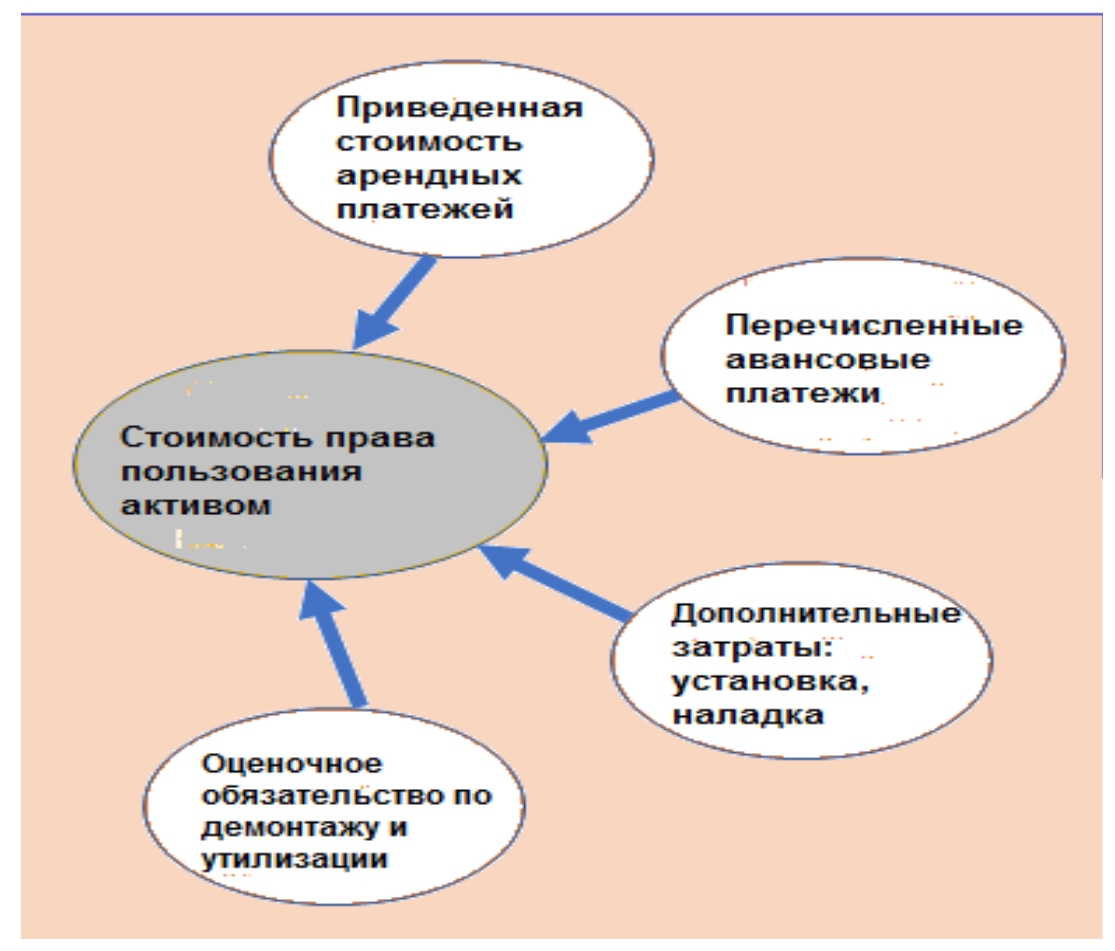

Puc. 4. Стоимость права пользования активом. 
Дисконтирование производится с применением ставки, при использовании которой приведенная стоимость будущих арсндных платсжсй и нсгарантированной ликвидационной стоимости предмета аренды становится равна справедливой стоимости предмета аренды.

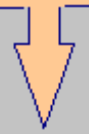

Негарантированной ликвидационной стоимостью считается предполагаемая справедливая стоимость предмета аренды, которую он будет иметь к концу срока аренды, за вычетом сумм, подлсжащих уплатс или получснию в связи с гарантиями выкупа предмета аренды по окончании срока аренды, которые учтены в составе арендных платежей.

Рис. 5. Дисконтирование арендных платежей.

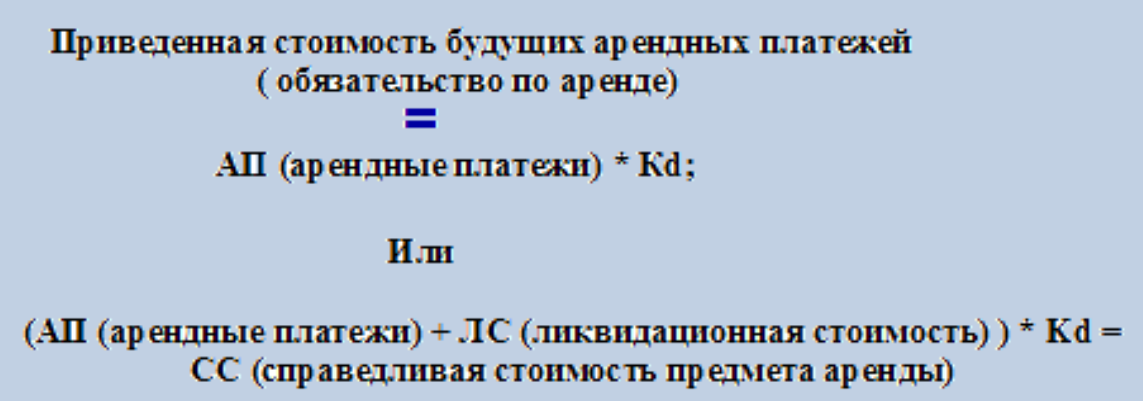

Pис. 6. Приведенная стоимость будущих арендных платежей.

Текущая приведенная стоимость одного будущего денежного потока может рассчитываться так же по формуле [3]:

$$
V=A /(1+R)^{\wedge T}
$$

где V - текущая приведенная стоимость арендного платежа;

А - номинальная величина арендного платежа (без учета НДС);

$\mathrm{R}$ - ставка дисконтирования за месяц;

$\mathrm{T}$ - время от момента оценки до момента платежа (количество месяцев до даты платежа).

Рассмотрим пример расчета ставки дисконтирования, будущих платежей по договору аренды, заключенному на три года.

Для примера рассмотрим договор аренды неуникального оборудования, предположим, нам известна справедливая стоимость оборудования на начало срока аренды. А так же известно: 12,00 количество периодов (кварталов) - 3 года с ежеквартальными платежами; 240000,00 ежеквар- тальный платеж (без НДС); 2500 000,00 справедливая (рыночная) стоимость на дату передачи оборудования (начала аренды); 500 000,00 негарантированная ликвидационная стоимость через 3 года.

Сначала рассчитывается ставка дисконтирования, на основании исходных начальных данных, как показано в таблице 1.

Затем, зная ставку дисконтирования, рассчитывается приведенная стоимость будущих платежей по аренде или обязательство по аренде, как показано в таблице 2.

В нашем примере право пользования активом или обязательство по аренде принимается к учету, в момент признания объекта учета аренды, в сумме 2201 600, 51 руб.

Сумма права пользования активом может быть увеличена, если были авансовые платежи, затраты по наладке оборудования, а также на сумму оценочного обязательства по разборке и демонтажу оборудования в конце срока аренды.

Как видно, расчет достаточно сложный, по- 
Таблица 1. Расчет ставки дисконтирования на основании данных договора аренды.

\begin{tabular}{|c|c|c|c|}
\hline \multicolumn{2}{|c|}{ СТАВКА ДИСКОНТИРОВАНИЯ } & & $4,3955 \%$ \\
\hline \multicolumn{3}{|c|}{$4,395 \%$} & \\
\hline ПЕРИОД & РЕАЛЬНЫЙ ПОТОК & ДИСКОНТИРОВАННЫЙ ПОТОК & \\
\hline 1 & 240000,00 & 229895,06 & \\
\hline 2 & 240000,00 & 220215,57 & \\
\hline 3 & 240000,00 & 210943,63 & \\
\hline 4 & 240000,00 & 202062,07 & \\
\hline 5 & 240000,00 & 193554,46 & \\
\hline 6 & 240000,00 & 185405,06 & \\
\hline 7 & 240000,00 & 177598,77 & \\
\hline 8 & 240000,00 & 170121,17 & \\
\hline 9 & 240000,00 & 162958,40 & \\
\hline 10 & 240000,00 & 156097,21 & \\
\hline 11 & 240000,00 & 149524,90 & \\
\hline 12 & 740000,00 & 441623,72 & \\
\hline СУММА & 3380000,00 & 2500000,00 & \\
\hline
\end{tabular}

Таблиц̧ 2. Расчет приведенной стоимости будущих платежей по договору аренды неуникального оборудования.

\begin{tabular}{|c|c|c|c|c|c|}
\hline & \multicolumn{2}{|c|}{ Сумма всех платежей по аренде = } & & & \multirow{2}{*}{$\begin{array}{r}2880000,00 \\
\mathbf{2 2 0 1 6 0 0 , 5 1}\end{array}$} \\
\hline \multicolumn{5}{|c|}{ Приведенная сумма будущих платежей (обязательство арендатора) = } & \\
\hline \multicolumn{5}{|c|}{ Приведенная сумма будущих платежей (обязательство арендатора): } & \\
\hline ПЕРИОД & КЗ на начало & $\% \%$ & платеж & КЗ на конец & \\
\hline 1 & 2201600,51 & 96770,46 & 240000,00 & 2058370,97 & \\
\hline 2 & 2058370,97 & 90474,87 & 240000,00 & 1908845,84 & \\
\hline 3 & 1908845,84 & 83902,55 & 240000,00 & 1752748,39 & \\
\hline 4 & 1752748,39 & 77041,35 & 240000,00 & 1589789,73 & \\
\hline 5 & 1589789,73 & 69878,57 & 240000,00 & 1419668,30 & \\
\hline 6 & 1419668,30 & 62400,95 & 240000,00 & 1242069,25 & \\
\hline 7 & 1242069,25 & 54594,65 & 240000,00 & 1056663,90 & \\
\hline 8 & 1056663,90 & 46445,24 & 240000,00 & 863109,14 & \\
\hline 9 & 863109,14 & 37937,61 & 240000,00 & 661046,75 & \\
\hline 10 & 661046,75 & 29056,04 & 240000,00 & 450102,80 & \\
\hline 11 & 450102,80 & 19784,09 & 240000,00 & 229886,88 & \\
\hline 12 & 229886,88 & 10104,59 & 240000,00 & $-8,53$ & \\
\hline
\end{tabular}

этому в стандарте предлагается другой вариант расчета приведенной стоимости, применяя ставку по которой арендатор мог бы привлечь заемные средства на сопоставимый период, но для этого надо провести анализ предлагаемых ставок по кредитам различных банков и организаций.

Новый объект учета - право пользования активом принимается к учету как внеоборотный актив и начинает амортизироваться по правилам амортизации основных средств. Поэтому в учете, помимо нового объекта учета в активе, объект учета в виде обязательства по аренде также появляется и в пассиве. И право пользования активом, амортизируясь, уменьшает свою балансовую стоимость, так же как и обязательство по аренде уменьшается погашением арендных платежей.

Таким образом, можно сказать, что происходят значительные изменения в структуре бухгалтерского баланса, утяжеляется и актив и пассив баланса, а это приводит и к изменению структуры финансовых показателей и, как следствие, к изменению критериев, например отне- 
сения компаний к обязательно аудируемым, что показано на рисунке 7.

Подводя итог, можно сказать, что новый стандарт не просто новый, он не только противоречит правилам традиционно российского учета, но и вводит слишком много оценочных и расчетных значений и показателей, в ряде случаев допускающих субъективное толкование. В результате бухгалтерский учет усложняется, бухгалтерская работа становится с внедрением новых стандартов расчетной и оценочной, а также и достаточно субъективной[5].

Те организации, которые должны вести учет по правилам МСФО его и так ведут и формируют свою отчетность[4]. Как показывает прак- тика, в организациях, где это не требовалось, очень небольшое количество компаний в этом 2021 году начало применять ФСБУ 25/2018.

Очевидно, что стратегия сближения и перехода российской системы бухгалтерского учета на МСФО, внедрение в российскую практику учета новых стандартов ФСБУ должно проходить постепенно, планомерно, внедряя в отечественную практику учета все самое прогрессивное. При этом важно не потерять традиционный опыт российского учета. Эти процессы должны сопровождаться переходными положениями, анализом эффективности применения новых правил и требований бухгалтерского учета, в соответствии с классическим принципом “не навреди”.

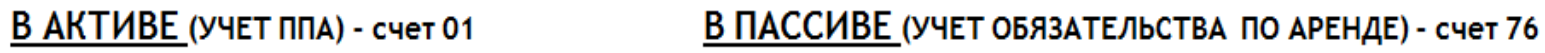 \\ ПЕРВОНАЧАЛЬНО:}

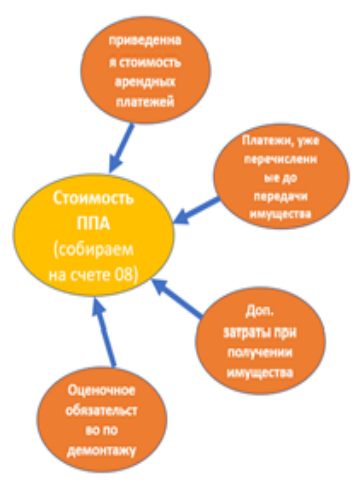

ИЗМЕНЕНИЕ ПОКАЗАТЕЛЕЙ (ЕЖЕМЕСЯЧНО/ЕЖЕКВАРТАЛЬНО/ЕЖЕГОДНО):
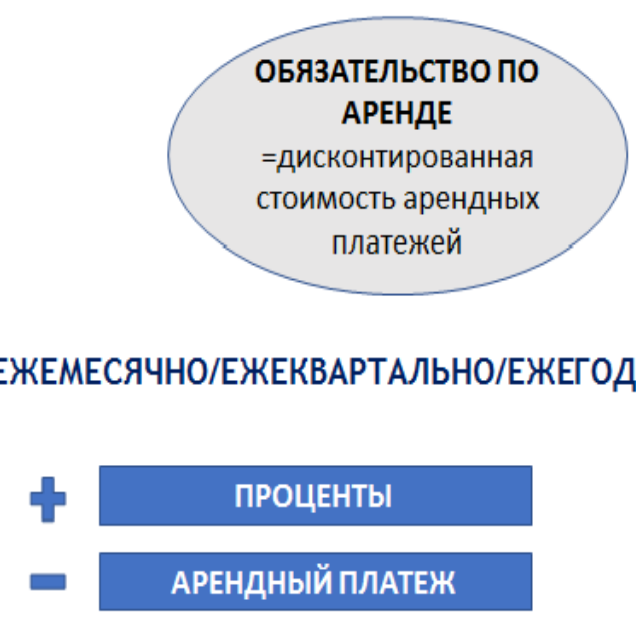

Puc. 7. Изменения в структуре бухгалтерского баланса при признании ППА и АО.

\section{Библиографический список}

1. Федеральный закон от 06.12.2011 N 402-ФЗ (ред. от 26.07.2019) «О бухгалтерском учете»// СПС КонсультантПлюс.

2. Приказ Минфина России от 16.10.2018 N 208н «Об утверждении Федерального стандарта бухгалтерского учета ФСБУ 25/2018 «Бухгалтерский учет аренды» // СПС КонсультантПлюс.

3. Рекомендация Р-65/2015-КпР «Ставка дисконтирования»// http://bmcenter.ru/Files/R-KpT-Opredeleniye_ stavki_diskontirovaniya

4. Голышева Н.И., Чотчаева А.М. (2019) - Проблемы построения процесса ведения учета и формирования отчетности в формате МСФО на предприятии нефтегазовой отрасли. Экономика. Бизнес. Банки. 2019. 4(30) апрель. С. 66-80.

5. Голышева Н.И. (2021) - Проблемы гармонизации бухгалтерского и налогового учета. Экономика. Бизнес. Банки. 2021.08(58) август. С. 29-37. 